\title{
Intercultural Sensitivity as Condition of Academic Mobility Success
}

\author{
N.S. Sakharova \\ Foreign Languages Department \\ Orenburg State University \\ Orenburg, Russia \\ vnimot@yandex.ru \\ N.V.Yankina \\ Foreign Languages Department \\ Orenburg State University \\ Orenburg, Russia
}

\author{
V.V. Moroz \\ Foreign Languages Department \\ Orenburg State University \\ Orenburg, Russia \\ V.V. Tomin \\ Foreign Languages Department \\ Orenburg State University \\ Orenburg, Russia
}

\author{
E.V. Dmitrieva \\ Foreign Languages Department \\ Orenburg State University \\ Orenburg, Russia
}

\begin{abstract}
In the modern education, the ties between universities get stronger, the opportunities to study abroad enlarge, the number of academic mobility programs increases exposing students to different cultures. The development of students' key competencies, including intercultural competence, is one of the principal goals of higher educational institutions. The issue of intercultural competence development as the ability to create a harmonious and productive relationship with the representatives of various cultures is getting more relevant since people have become more mobile than ever before. The authors focus on the features and critical stages of intercultural sensitivity development being one of the components of intercultural competence. Some methods based on M. Bennett's Development Model of Intercultural Sensitivity are suggested to enhance this personal characteristic. The authors argue that short-term educational programs abroad increase the intercultural sensitivity level. Intercultural Sensitivity Index and Likert scale used in the research helped to assess the changes in students' intercultural sensitivity development. The set of methods both qualitative and quantitative contributed to determining the features characteristic of the academic mobility students: willingness to enhance communicative skills, readiness to acquire different behavior patterns, respect for other cultural values, points of view and outlooks, the necessity to improve language proficiency.
\end{abstract}

Keywords-higher education, intercultural sensitivity, academic mobility, intercultural competence, cultural values

\section{INTRODUCTION}

Globalization and internationalization of higher education led to new priorities when developing new educational strategies. Academic mobility has become a key element of the process and enabled both students and teaching staff to study and teach outside the country.

The outgoing mobility of students is a primary indicator whether university's training programs correlate with the ones in other institutions and provide a wider opportunity for its students to develop their personality and maturity, interaction and professional skills.

Together with many positives effects, the academic mobility faces many challenges as well, for example, meeting visa regulations, recognition of academic achievements, language proficiency, costs, and introduction to a new culture. The latter is one of the variables that prepare students for successful studies abroad.

\section{THEORETICAL FRAMEWORK}

The need and wish to socialize in a hosting community make intercultural communication and competence the subject of studies in many areas of knowledge like sociology, culturology, personality psychology, linguistic didactics, general linguistics and, recently, linguistic culturology and communication theory by such scientists as E.M. Vereshchagin, V.G. Kostomarov, V.I. Karasik, V.V. Krasnykh, E.G. Kreidlin, T.V. Larina. N.L. Shamne and others $[1,2]$.

According to the D. Deardorff's definition, intercultural communication is "the ability to communicate efficiently and appropriately in intercultural situations based on one's crosscultural knowledge, skills, and attitudes." The specific features of intercultural communication are curiosity, openness, respect for other cultures [3]. 
There are three aspects of intercultural competence: cognitive reflecting in cultural awareness, behavioral revealing in cross-cultural skills and emotional represented by intercultural sensitivity [4].

Intercultural awareness is the knowledge and understanding of cultural peculiarities and traditions affecting people's behavior and consciousness. Intercultural sensitivity is the person's ability to develop a positive attitude to the understanding of cultural differences to act effectively in the cross-cultural interaction process [5]. Intercultural skills present the set of verbal and non-verbal behavioral patterns in intercultural situations [6]. One should note that in this case the behavior is determined by knowledge and emotions. Researchers have ignored the study of the emotional component of intercultural communication for quite a while, though it seems to be a very particular dominant feature of a national character and national biases in any culture. As the practice of intercultural competence acquisition shows, it is the emotional aspect that is hard to develop since it should be entirely or partially changed [7].

In his model of intercultural sensitivity development, M. Bennett explained this process as the phased transition from ethnocentrism to ethnorelativism [8].

Ethnocentrism in the field of cultural anthropology means the system of notions of one's community and culture as being central and dominant concerning other cultures. So, at the first stage of acquaintance with a new culture, there is a denial of cultural differences between nations. This may result in either separation or isolation.

At the isolation stage, cultural differences are not felt or perceived in a new cultural environment. To illustrate this, one may think of tourists traveling abroad; they try to find similarities with their culture, and that is why they notice only familiar or usual things. Therefore, isolation may be partial. For example, applying broad and general categories for cultural differentiation, people quickly recognize the Europeans among the Asians, but would hardly distinguish the Japanese from the Koreans and so on. Separation is the distancing the differences from the native culture by physical or social barriers. The example of separation is the people segregation according to their political views, racial, religious or other features. The downside of separation is the perception of different people as belonging to a lower social category. To form the intercultural sensitivity at this stage, it is vital to give and get information about different cultures through art, music, movies and so on as much as possible [9]. However, as soon as cultural differences are being recognized, there is tension which is characteristic of the next stage - defense.

The initial stage of defense is the critic of an alien culture in general and its representatives. The feeling of one's cultural superiority (pride of one's nation and country) may remain. The other extreme of the defense stage is the humiliation of one's culture. It is especially characteristic of the people living for a long time in a foreign culture. At the defense stage, it is important to enlarge the knowledge of a native culture diversity as well as to find universal features of various cultures. If the cultural difference minimization stage does not follow the defense stage, then the extinction of intercultural development is to be stated.

The minimization stage embodies the idea that cultures are similar because of the physical universalism (one head, two legs, two arms), universal needs (in food, shelter, social recognition), universal behavior. Nevertheless, the representatives of different cultures live and act in various culturally determined social contexts and the absence of willingness or inability to recognize that proves the ethnocentric character of this stage [10].

The further learning of cultures occurs from the position of ethnorelativism based on the assumption that a human's behavior can be understood considering the norms of a particular culture. At the first ethnorelativism stage of approval, the external (for instance, in behavior) as well as internal (cultural values) differences are recognized. It may be difficult to interact with people that are different because of the reluctance or fear. Direct contact with another culture (traveling, education, job, life in a host family) will prepare students to the next stage that is the adaptation. Adaptation means the existence and the use of several behavioral patterns depending on the cultural context of living [11]. The beginning of this stage is empathy (willingness to feel with the others), and the end is pluralism (the ability to act according to the cultural diversity). At the integration stage, another culture is felt and perceived as one's own.

\section{MATERIALS AND METHODS}

The process of moving from one stage of intercultural sensitivity development to the other is achieved by specially designed educational programs and methods.

The system of methods consists of two groups: didactic (guidance, orientation, education) and empiric (case study, role-play, and training). Though the educational methods are of great significance, they are not always efficient because of the subjective information and passive learning. Empiric methods, on the contrary, imply acting in real-life situations of intercultural communication based on the analysis and interpretation of a different person's behavior.

The modern process of globalization makes it necessary to provide education with a broad polyculture context of a modern specialist's professional activity [12]. That is why the curricula of such subjects as "Business Cultures in the International Business," "Culturology," "World Religions and Cultures," "Region Studies," "Theory and Practice of Intercultural Communication," "Philosophy," etc. were enriched by the issues of intercultural interaction. Along with the traditional educational techniques such as lectures, seminars, and training, education abroad is getting more popular since it provides students with the opportunity not only to perceive the diversity of cultures but also to study how to live and work in the new environment.

\section{RESULTS}

According to the International Education Institute, the number of students studying abroad has increased by $150 \%$ for the last decade and was more than 4,5 million people in 2012 [13]. It is worth noting that only $4 \%$ of students choose 
the long-term educational programs (academic courses, cultural or volunteer projects, etc.). The popularity of shortterm educational programs can be explained by several reasons. These are a reasonable price, the absence of the need to make a break in the general educational course, the acquisition of credits required for the certification in the home university, the opportunity to return home in case of some urgency (health problems, family circumstances), etc. [14].

According to M. Bennett, the level of intercultural competence, as well as intercultural sensitivity, increases while the experience of intercultural communication enlarges [8]. The authors conducted some research on how short-term educational programs affect the level of students' intercultural sensitivity. The diagnostics of the level was performed twice before and after a short training course taken in Great Britain, Germany, Finland, France, and Japan in 2012-2016. Sixtythree students majoring in Economics participated in the research. The participation of these students in academic mobility programs is determined by the fact that the modern economic development in any country cannot be imagined without international business and trade sector. That is why the professional interests of the economists are inseparably linked with such notions as intercultural efficiency, the integral part of which is intercultural sensitivity.

The initial and final level of intercultural sensitivity was determined according to intercultural sensitivity development (denial - defense - minimization - acceptance - adaptation integration) [15].

The Likert Scale was used for the answers where 5 strongly agree, 4 - agree, 3 - neutral, 4 - disagree, 1 - strongly disagree. After filling in the questionnaires, the average score of students' answers at each stage of research was determined. The correlation of survey results before and after a short-term educational program was calculated. Particular attention was paid to those answers that showed the highest score and the greatest deviation. The results are presented in table I.

\section{DISCUSSION}

According to the authors' research data, most students had some idea of the diversity of cultures, respected and understood different points of view and outlooks before the short-term educational program. The high percentage of highest possible answers at the acceptance stage can be explained by the multi-ethnicity of the region and the university, by the abundance and access to the ethnically marked information in the media and by the previous experience of traveling abroad.

No one had chosen the highest possible score for the answers at the defense stage. The students do not think that their values may be threatened while communicating with foreigners, do not consider their or different culture to be the best possible, do not believe that negative attitude to any culture is appropriate. The indicators here turn to be significant.
TABLE I. THE CHOICE OF THE MAX ANSWER IN THE LIKERT SCALE

\begin{tabular}{|c|c|c|c|}
\hline $\begin{array}{l}\text { The stages of } \\
\text { intercultural } \\
\text { sensitivity } \\
\text { development }\end{array}$ & $\begin{array}{l}\text { Question } \\
\text { number }\end{array}$ & $\begin{array}{c}\text { Before short } \\
\text { academic } \\
\text { mobility } \\
\text { program, \% }\end{array}$ & $\begin{array}{c}\text { After short } \\
\text { academic } \\
\text { mobility } \\
\text { program, \% }\end{array}$ \\
\hline \multirow{4}{*}{ Denial } & 1 & 50.5 & 17.9 \\
\hline & 2 & 0.0 & 0.0 \\
\hline & 3 & 12.5 & 0.0 \\
\hline & 4 & 0.0 & 0.0 \\
\hline \multirow{5}{*}{ Defense } & 5 & 0.0 & 0.0 \\
\hline & 6 & 0.0 & 0.0 \\
\hline & 7 & 0.0 & 0.0 \\
\hline & 8 & 0.0 & 0.0 \\
\hline & 9 & 0.0 & 0.0 \\
\hline \multirow{4}{*}{ Minimization } & 10 & 15.9 & 43.5 \\
\hline & 11 & 0.0 & 0.0 \\
\hline & 12 & 7.4 & 2.1 \\
\hline & 13 & 25.0 & 10.2 \\
\hline \multirow{4}{*}{ Acceptance } & 14 & 54.5 & 89.1 \\
\hline & 15 & 51.7 & 75.0 \\
\hline & 16 & 27.3 & 47.9 \\
\hline & 17 & 31.7 & 60.5 \\
\hline \multirow{4}{*}{ Adaptation } & 18 & 27.0 & 39.5 \\
\hline & 19 & 31.9 & 63.3 \\
\hline & 20 & 22.0 & 36.7 \\
\hline & 21 & 40.0 & 56.0 \\
\hline \multirow{3}{*}{ Integration } & 22 & 0.0 & 0.0 \\
\hline & 23 & 23.7 & 36.9 \\
\hline & 24 & 13.5 & 18.1 \\
\hline
\end{tabular}

More than half of all respondents agreed that they do not see any obvious cultural differences, and $25 \%$ of students assumed that there are more similarities than diversities between people of various nationalities. We believe that students are not quite aware of cultural peculiarities that affect communication process.

Relatively many answers with the highest possible score to the questions describing phases of adaptation and integration were recorded at the first stage of the diagnostics. For example, the students were ready to change their verbal and non-verbal behavior to fit their communicator's behavior, to give up their outlook pattern for some time and to accept different model, to take decisions by the analysis and comparison of cultural context. This change became possible due to the specific preliminary guidance on the basics of intercultural communication, which is obligatory for the students planning to study abroad [16]. The fact that students initially learned about the necessity for adaptation and integration only in theory was proved by the diagnostics data collected after the completion of training abroad [17]. It is at these very stages the increase of positive answers was significant. Indeed, one can easily imagine what is to happen in theory but could hardly change one's emotions or behavior to fit the norms and values of the foreign culture in real-life situations.

The data of the second stage of the research showed that the greatest changes took place at the acceptance stage; students while studying abroad realized the heterogeneity of native and foreign cultures caused by the different cultural experience of its representatives. The number of students being at the denial stage reduced significantly. So, before going abroad, $12.5 \%$ of students agreed that they feel at ease 
with people like themselves (in appearance and behavior), but having completed their academic mobility program, nobody chose this statement as "strongly agree." Moreover, the number of students not recognizing the cultural diversity reduced more than two times.

In this research, the authors used both quantitative and qualitative assessment methods of students' intercultural sensitivity, namely, essays, diaries, portfolios. They analyzed students' essays to understand how students make their decisions, set and achieve goals, assess their experience of intercultural communication while planning and carrying out their training abroad. It should be noted that students being aware of the importance of foreign language skills in the modern world take long-term language courses at the university or short-term ones abroad [18]. Students are interested not only in the traditional European languages such as English, German, French, Spanish but the Asian ones as well.

Intercultural sensitivity is manifested differently, for example, two students studying Japanese at the native university had a short-term and a long-termed training in Japan. On coming home from this "incredibly beautiful and mysterious country," one student still could not adapt to this culture and gave up further training while the second student kept on participating in all activities of the University Center for Japanese Studies which became her "second family."

The development of intercultural communication is enhanced due to the classes, lectures, workshops and drama activities conducted by the native speakers from the UK, the USA, Germany, France, Spain, Japan, and China. The students having attended all these events before their studying abroad appreciate this opportunity to develop their communicative skills.

It is worth noting that frequently students having completed one program of academic mobility in one country make up their mind to continue their education in a different cultural environment [19]. For example, one student after a short-term training in Japan went to Germany for two semesters. Some students having had completed several programs of academic mobility during their studies at home university, went abroad to get their Master's degree.

Analyzing the essays, the authors found out that the aim of the students participating in the programs of academic mobility is not only to improve their language and professional skills that would attract their prospect employers. Besides students recognized that they got positive intercultural communication experience, mastered their language and understood people of different cultures better. Most students pointed out that academic mobility programs gave them the opportunity not only to study at a foreign university but also to learn more about the country, the culture, they had read or heard about so much.

The authors assume that the value of openness to everything new turns into the motivation to see the world and the goal to visit the country of interest. On returning home, students feel confident speaking a foreign language having overcome the language barrier, their aim is to master their communicative competence. Students learn a lot from their academic mobility experience and their intercultural transition; they realize the changes that took place: exemption from cultural stereotypes, openness to something new, value recognition, acceptance of other people's values, empathy. The academic mobility experience allows students to perceive the world differently, to move further in their cultural development.

\section{CONCLUSIONS}

Thus, the authors' research proved that short-term educational programs abroad enhance intercultural sensitivity development.

The process of cognition and acceptance of different culture starts at the very beginning of their staying in a foreign country since students have to face some specific culturally determined issues as the peculiarities of migration legislation and visa procedures, the transportation and banking system, the language and social barriers in communication. Besides the more intense interpersonal contacts are, the higher the level of intercultural sensitivity is. For example, students living in multinational dormitories or host families have higher intercultural sensitivity than those who only rent an apartment in a multinational district or town.

It goes without saying that the higher the level of intercultural sensitivity is, the more actively students participate in different international activities held by the University: festivals, conferences, training, exhibitions, and fairs.

The methods mentioned above can be used in short-term educational programs designing, their efficiency assessment from the intercultural sensitivity point of view as well as general outcomes of university students' studies planning.

\section{References}

[1] G. Hofstede, Cultures, and Organizations: Software of the Mind, 2nd ed. McGraw-Hill: USA, 2005.

[2] V.I. Shakhovskiy, Linguistic Theory of Emotions, Moscow: Gnosis, 2008.

[3] D. K. Deardorff, "Identification and assessment of intercultural competence as a student outcome of internationalization," Journal of Studies in International Education, vol. 10, No. 3, pp. 241-266, 2006.

[4] A.P. Sadokhin, Introduction into the Theory of Intercultural Communication, Moscow: Vishaya shkola, 2005.

[5] N.V. Yankina, "The role of students' intercultural sensitivity development in a globalized environment," Bulletin of Orenburg State University, is. 2, pp. 178- 183,2015.

[6] A.Yu. Bogomolova, N.V. Eremina, "Interaction in speech activity development of non-linguistic specialties students," World of Science Internet-journal, No. 2, 2016.

[7] T.S. Bochkareva, "Formation of students' foreign language competence in the information field of cross-cultural interaction," Modern Research of Social Issues, No. 6, 2015.

[8] J.M. Bennett, M.J. Bennett, D. Landis "Developing intercultural sensitivity: an integrative approach to global and domestic diversity," Handbook of Intercultural Learning, 3rd ed., Eds. T. Oaks, CA: Sage, 2004, pp. 147-165. 
[9] Ch. Demetry, R. Vaz, "Influence of an education abroad program on the intercultural sensitivity of STEM undergraduates: a mixed methods study," Advances in Engineering Education, vol. 6, is. 1, Spring 2017.

[10] E. Gonzalez, K. Pang, G. Sweeney, A. Wang, "Studying abroad and willingness to relocate overseas," Pepperdine Journal of Communication Research, vol. 5, article 13, 2017.

[11] S. López-Rocha, "Intercultural communicative competence: creating awareness and promoting skills in the language classroom," C. Goria, O. Speicher and S. Stollhans, Eds. Dublin: Research-publishing.net, 2016, pp. 105-111.

[12] A.V. Kiryakova, "University education in globalization context," Universitetskyi okrug, is. 10, pp. 16-19, 2007.

[13] B. E. Zarnick, "Short-term study abroad programs and the development of intercultural sensitivity," unpublished.

[14] M. Ueberwimmer, H. Hofstadler and S. Weisinger, "An analysis of the differences in business students' intercultural sensitivity in two degree programs," Literacy Information and Computer Education Journal, is. 3, vol. 3, pp. 667-674, September 2012.
[15] C.L. Olson, K.R. Kroeger, "Global competency and intercultural sensitivity," Journal of Studies on International Education, № 5, pp. 116137, 2001.

[16] A.N. Ksenofontova, "Internet dialogue and media interaction in students' speech activity development," Bulletin of Orenburg State University, 12, pp. 54-59, 2005.

[17] N.V. Eremina, O.V. Kabanova, G.V. Terekhova, "Intercultural adaptation of students in the information field of cross-cultural interaction," Global Media Journal, Special Issue S2:7, pp. 2-10, 2016.

[18] V.V. Moroz, "Creative approach to English for specific purposes teaching," Bulletin of Orenburg State University, vol. 2 (202), pp. 8-12, 2017.

[19] A.A. Polyanskaya, "Intercultural communication as a modern scientific field," Current issues of linguistics and didactics: conceptions and perspectives: The Proceedings of the 6-th International Scientific and Practical Conference, April 30 - May 15, 2016, Volgograd, Russia, pp. 90-95. 